\title{
Internal dosimetry in F-18 FDG PET examinations based on long time measured organ activities using total-body PET/CT: dose it makes any difference from a short-time measurement?
}

\author{
Pengcheng Hu \\ Zhongshan Hospital Fudan University \\ Xin Lin \\ Institute of Radiation Medicine Fudan university \\ Weihai Zhuo \\ Institute of radiation medicine Fudan university \\ Hui Tan \\ Zhongshan Hospital Fudan University \\ Tianwu Xie \\ Institute Of Radiation Medicine Fudan University \\ Guobing Liu \\ Zhongshan Hospital Fudan University \\ Shuguang Chen \\ Zhongshan Hospital Fudan University \\ Xin Chen \\ Institute Of Radiation Medicine Fudan University \\ Haojun Yu \\ Zhongshan Hospital Fudan University \\ Hongcheng Shi ( $\nabla$ shihongcheng163@163.com ) \\ Zhongshan Hospital Fudan University https://orcid.org/0000-0003-1922-1359 \\ Haikuan Liu \\ Institute Of Radiation Medicine Fudan University
}

Original research

Keywords: time-activity curve, cumulated activity, organ absorbed dose, dynamic bladder wall absorbed dose, effective dose, Total-body positron emission tomography.

Posted Date: December 21st, 2020 
DOl: https://doi.org/10.21203/rs.3.rs-131050/v1

License: (c) (1) This work is licensed under a Creative Commons Attribution 4.0 International License. Read Full License

Version of Record: A version of this preprint was published at EJNMMI Physics on July 15th, 2021. See the published version at https://doi.org/10.1186/s40658-021-00395-2. 
Internal dosimetry in F-18 FDG PET examinations based on long time measured organ activities using total-body PET/CT: dose it makes any difference from a short-time measurement?

Pengcheng $\mathrm{Hu}^{1}$, Xin Lin (Co-Author) ${ }^{2}$, Weihai Zhuo ${ }^{2}$, Hui Tan ${ }^{1}$, Tianwu Xie ${ }^{2}$ Guobing Liu ${ }^{1}$, Shuguang Chen $^{1}$, Xin Chen ${ }^{2}$, Haojun $\mathrm{Yu}^{1}$, Hongcheng Shi (Correspondent) ${ }^{1}$, Haikuan Liu (Correspondent) ${ }^{2}$

${ }^{1}$ Department of nuclear medicine, Zhongshan Hospital, Fudan University, 1069 Xietu Road, 200032 Shanghai, China

${ }^{2}$ Institute of radiation medicine, Fudan Uniersity, 2094 Xietu Road, 200032 Shanghai, China

Pengcheng Hu and Xin Lin contributed equally to this work.

Hongcheng Shi, shi.hongcheng@ @s-hospital.sh.cn

Haikuan Liu, liuhk@fudan.edu.cn 


\section{Abstract \\ Purpose}

The 2-meter long total-body PET/CT scanner (UEXPLORER) has been developed recently while its total-body coverage and ultrahigh sensitivity provide opportunities for in vivo time-activity curve (TAC) measurement of all investigated organs with high temporal resolution simultaneously. This study aims at quantifying the cumulated activity and patient dose with long-time measured time-activity curves (TACs) of different organs, so that the comparison between estimation of quantifying methods using short-time or long-time TACs could be performed.

Methods

Organ TACs of 10 healthy volunteers were collected by the newly developed dynamic total-body PET/CT system in 4 periods after the intravenous injection of 2-[F-18]Fluoro-2-deoxy-D-glucose $\left({ }^{18} \mathrm{~F}-\mathrm{FDG}\right)$. The 8-hour TACs of 6 source organs were fitted by using a spline method. Comparing cumulated activity estimated from spline fitted curves, the cumulated activity estimated from multiexponential curve was also calculated. Exponential curve was fitted with shorter series of data consisting with clinical procedure and previous dosimetry works. An 8-hours dynamic bladder wall dose model considering 2 voiding were demonstrated to illustrate the differences in bladder dose caused by the different measurement durations. Organ absorbed doses were further estimated by using MIRD method and voxel phantoms for effective dose estimations.

\section{Results}

Short-time measurement could bring significant differences in estimated cumulated activity for liver compared with long-time measured spline fitted method while the differences of cumulated activity were $18.38 \%$ on average. For myocardium, the estimated cumulated activity difference was statistically neglectable due to the individual variation in metabolism. The average residence time differences of brain, heart, kidney, liver and lungs are $8.38 \%, 15.13 \%, 25.02 \%, 23.94 \%$ and $16.50 \%$ between spline fitted curve and multi-exponential fitted curve (fitted using the data from 57 minutes to 75 minutes after injection). When considering effective dose, the maximum differences of residence time between long-time measured spline fitted curve and multi-exponential fitted curve (fitted with shorter series of data) was $9.93 \%$. The bladder contributed the most to the effective dose among all the investigated organs with the value of $21.18 \%$. The bladder wall dose calculated using a long-time dynamic model was $13.79 \%$ larger than the twovoiding dynamic model, while at least $50.17 \%$ smaller than previous study using fixed bladder content volume.

\section{Conclusions}

Multi-organ TACs in-vivo long-time measurement with high temporal resolution by using total-body PET/CT proved that the data of clinical procedure with 20 minutes PET scan at 1 hour after injection could be used for retrospective dosimetry analysis. As the bladder content contributed the most to the effective dose, a long-time dynamic model was recommended for the bladder wall dose estimation.

Key words: time-activity curve - cumulated activity -organ absorbed dose - - dynamic bladder wall absorbed dose - effective dose - Total-body positron emission tomography. 


\section{Introduction}

Positron emission tomography (PET) provides unique information about the molecular and metabolic changes associated with disease [1]. Internal dosimetry is not only important in the radiation protection, but also in PET/CT developing, optimizing the dose - image quality and other clinical practices.

By means of dynamic acquisition over time, PET could measure the spatiotemporal distribution of radiotracers in vivo, which could be used for the organ TAC measurement and the absorbed dose investigation after the intravenous administration of 18F-FDG [2-8]. Based on previous TAC data [2-6], ICRP 106 reported a series of biokinetic data and administered activity to dose conversion factors [9]. After that, various of studies applied the recommended 18F-FDG biokinetic data or the administered activity to dose conversion factors to estimate patient internal radiation dose [10-14]. Also, voxel S-value-based method has been validated to be more accurate in dosimetry[15]. VSV method also required an accurate estimation of cumulated activity in voxel level.

However, the TAC data used for cumulated activity calculations and dose estimation in previous studies, which was collected either using traditional PET scanner or whole-body dynamic PET, had a relatively short duration. Studies using traditional scanner usually measured two or three organ activities, and consider the rest of the organs as part of the remainder of the body that has a uniform radioactivity distribution [2, 3, 5-8]. For dosimetry work using whole-body dynamic PET all acquired three to four frames of organ activity within 80 minutes[3, 4]. In most studies, multi-exponential functions with different assumptions were used to fitted the TACs of a rather short duration. Couple of dosimetry work assumed that the activity only decreased by physical decay after the last scan, while some considering the decreasing caused by biological disappearance after the last scan. The newly developed high sensitivity dynamic total-body scanner with an axial field of view of $194 \mathrm{~cm}$ and a transaxial field of view of $68.6 \mathrm{~cm}$ provided a head-to-toe dynamic PET scanning simultaneously $[16,17]$, which could help us to measure TAC of different organs in the same time line with high temporal resolution. The new measured TACs could be used to clarify the differences in cumulated activity caused by the duration of measurement and various assumptions.

Furthermore, all the studies mentioned above assumed that the bladder content volume stayed permanent, which could attribute significant differences in absorbed dose estimation in most cases [18, 17]. Wu et al. and Dowd et al. had built a dynamic bladder wall radiation dose model. The dynamic model considered that the bladder wall radiation dose caused by the content was a function of dynamic bladder volume and time activity of the bladder content. However, this model assumed that urine excretion following the first one or two voiding after the intravenous injection was not important in estimation of the absorbed dose of the bladder wall because of the short half-life period of 18F-FDG [19, 20, 18]. A two voiding model and 8 hours model was both considered in this study to clarified the differences caused by a rather short-time measurement of urine and bladder activity.

In this study, intermittently total-body dynamic PET scan that ended until eight hours after the intravenous injection was carried out using the newly developed scanner to obtain a quantification of the radioactivity of source organs. A comparison of cumulated activity, bladder dose and effective dose estimated using short-time measurement and 8 hours measurement was conducted.

\section{Materials and Methods}

Subjects. Having approved by the Medical Ethics Committee of Zhongshan Hospital, Fudan University and inform consented, ten healthy volunteers ( 7 men, 3 women; mean age: $55.7 \pm 9.5$ years (mean \pm standard deviation) without claustrophobia s participated in this study. The average height and weight of the male subjects were $166.9 \pm 3.7 \mathrm{~cm}$ (mean \pm standard deviation) and $63.6 \pm 8.6 \mathrm{~kg}$, respectively, and for female subjects were $153.7 \pm 7.5 \mathrm{~cm}$ and $56.2 \pm 7.4 \mathrm{~kg}$. Before performing the whole-body PET/CT scans, all of them were asked to refrain from any medication or eating at least for $6 \mathrm{~h}$, and their blood glucose were also determined.

Total-body PET scanning protocol. A 75 minutes dynamic scan was performed immediately after an intravenous injection of 18F-FDG according to body weight $(1.85 \mathrm{MBq} / \mathrm{kg})$ via the vein near the ankle. The list-mode PET data was acquired on a 194-cm long axial FOV total-body PET/CT (uEXPLORER, United Imaging Healthcare, Shanghai, China) [21]. The Low-dose CT scans were obtained for attenuation correction and all corrections applied to the reconstructed images. To make the most of the high temporal resolution of the scanner, the data set was divided into 60 frames: $36 \times 5 \mathrm{sec}, 24 \times 180 \mathrm{sec}$. Another three PET scans of 15 $\min$ for each subject were conducted approximately at 150,300 and 480 minutes after the intravenous injection. These three scans were each divided into 5 frames: $5 \times 180 \mathrm{sec}$. An example of reconstructed dynamic PET images in 4 periods for a single subject is 
shown in FIGURE.1. All PET images were reconstructed using ordered subset expectation maximization algorithm with the following parameters: TOF and PSF modeling, 2 iterations and 20 subsets, matrix $192 \times 192$, slice thickness $2.89 \mathrm{~mm}$, FOV 600 $\mathrm{mm}$ (pixel size $3.125 \times 3.125 \times 2.89 \mathrm{~mm}$ ) with a Gaussian post-filter $(3 \mathrm{~mm}$ ), and all necessary corrections, such as attenuation and scatter correction. All images were transferred to a commercial medical image processing workstation (uWS-MI, United Imaging Healthcare) for the image evaluation.

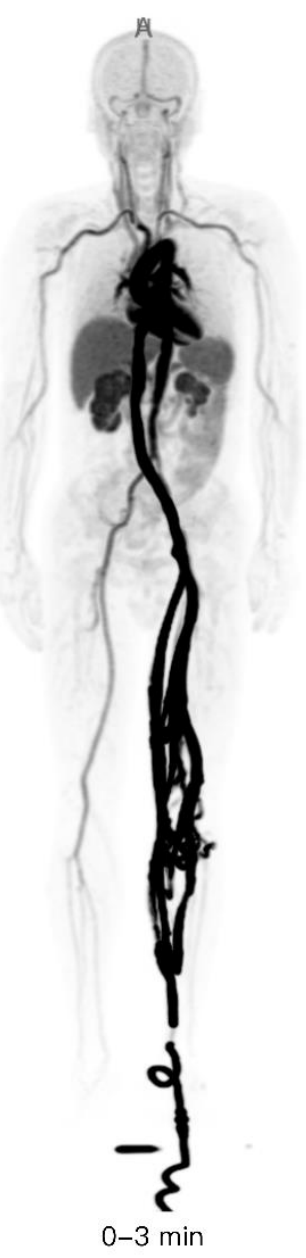

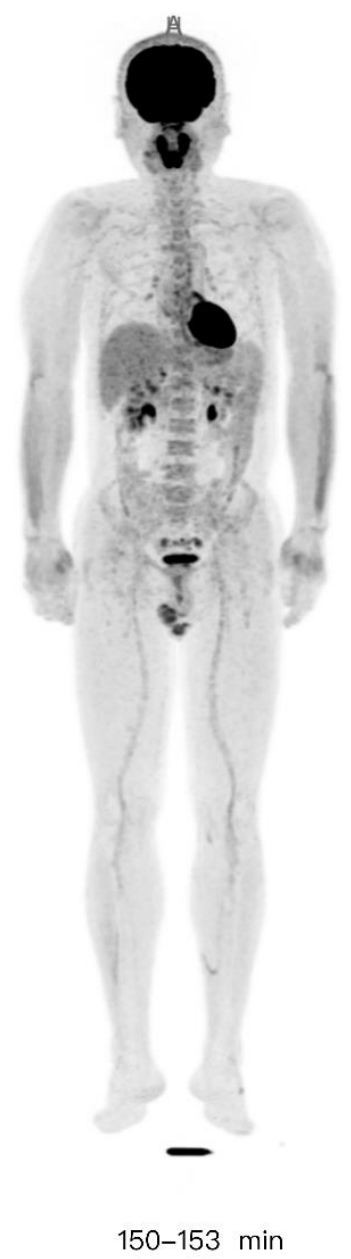

150-153 $\min$

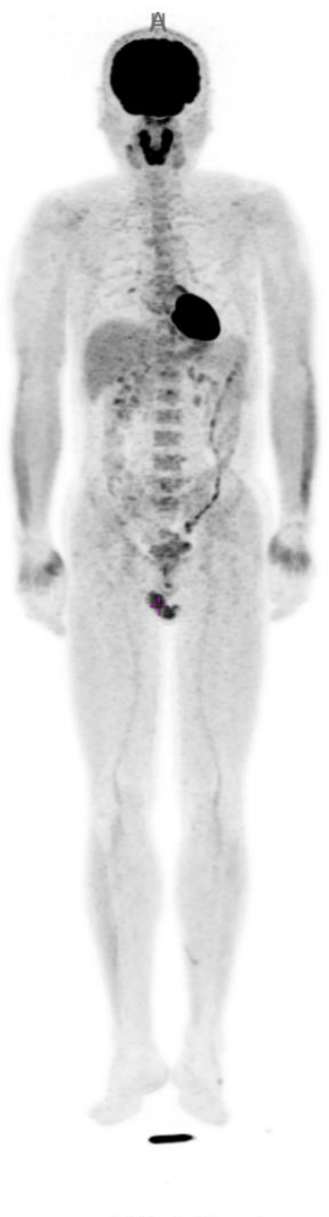

300-303 $\mathrm{min}$

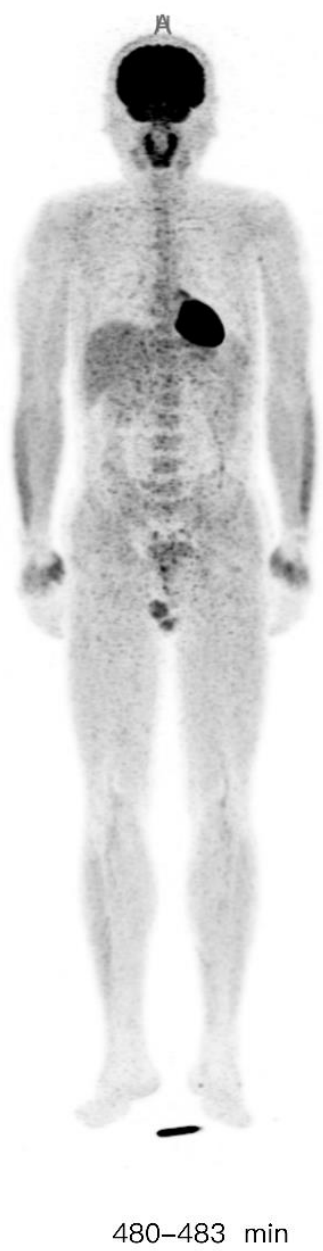

FIGURE.1. Reconstructed dynamic PET images (Ordered Subset Expectation-maximization Maximum-intensity

Projection) of early 3 minute, 150 153 minute, 300 303 minute, 480 483minute.

Organ time-activity curve measurement. The radioactivity in various source organs were obtained from reconstructed dynamic PET and low-dose CT fused images by contouring the shape of organs in those slices in which the organs were found. Contouring method was based on the study by Deloar H.M. et al. [4] The TACs of total 6 source organs in each subject, including brain, heart (left ventricle myocardium only), kidneys, liver, lungs and urinary bladder, were obtained. VOI analysis was carried out with a builtin PET image analysis software uWS-MI. To make sure the accuracy of the activity, a radioactive standard source was used to calibrate the activity.

Cumulated activity calculations. The nature of decay and also most of the metabolic processes is exponential, which makes it always possible to fit the curve into a complicated form of multi-exponential function[2-4, 7]. However, the time-activity curves represented by a sum of temporal basis functions, for instance, B-splines, had been widely used in parametric estimation in dynamic PET [22-24]. Therefore, for spline method, the area under TAC was calculated as follows:

$$
\widetilde{A_{s}}=\int_{0}^{T} A(t) d t+\int_{T}^{\infty} A_{f} e^{-\lambda t} d t
$$

where $\widetilde{A_{s}}$ is the cumulated activity in brain, kidney, lungs, liver, heart (left ventricle myocardium), $A(\mathrm{t})$ is the spline fitted activity 
curve, $A_{f}$ is the activity of the organ at the end of the last PET scan when the emission scan was assumed to begin to decrease only by physical decay and $\lambda$ is the physical decay constant.

The spline fitting and mathematical integration process was done using Origin (version 8.1).

$A_{u}(t)$, the time activity curve for urine remained in the urinary bladder, was fitted with the sum of two exponentially decaying functions and one constant as follows:

$$
A_{u}(t)=e^{-\lambda t} \times\left(A_{1} e^{-k_{1} t}+A_{2} e^{-k_{2} t}+C\right)-\sum_{i=1}^{\infty} \varepsilon\left(t-T_{i}\right) A_{u r}(t)
$$

where $A_{1}$ and $A_{2}$ are the intercepts, $k_{1}, k_{2}$ are biological elimination constants, $\varepsilon(t)$ is Heaviside function, $T_{\mathrm{i}}$ is the $i$ th urinary voiding time, and $A_{u r}(t)$ is the activity of urine excreted out of the body.

To compared the spline method with multi-exponential method, multi-exponential methods using different data was used to estimate the residence time. The time-activity curves were fitted as previous studies[4].

To fit the above function, 12 frames of the organ activity data were selected from 0 minutes to 60 minutes: $12 * 120$ s as described in previous studies[2, 7, 3], and the data at 10,40, 70 minutes: $3 * 180$ s were also used for comparison[4].

In clinical procedure, a PET scan of about 20 minutes at 1 hour after injection was conducted for most patients. To evaluate the possibility of individual dose estimation for every patient, $5 * 180$ s frames of date from 57 minutes to 75 minutes was used to estimate the cumulated activity to compared with the estimation using a long-time measurement.

Bladder wall absorbed dose calculation. Previous studies showed the S-value brings the most uncertainty in internal dose calculation of bladder wall absorbed dose among all the organs $[16,17]$. In this study, the absorbed dose of bladder wall that was caused by other organs was calculated using S-value obtained from Monte-Carlo simulation. The absorbed dose for the bladder content irradiating the bladder wall was calculated using the dynamic model which is a function of volume and activity of the bladder content. A dynamic absorbed dose calculation method was based on the assumption that the bladder wall is primarily contributed by two parts of irradiation: the gamma photons and beta particles $[25,19,26,18]$. The average bladder wall dose per unit administered activity was described as followed,

$$
\frac{D_{s}}{A_{0}}=\frac{1}{A_{0}} \int\left[D_{\gamma}(i)+D_{\beta}(i)\right] d t=\frac{1}{A_{0}} \int\left[\frac{\phi_{\gamma} A_{b}(t)}{(36 \pi)^{1 / 3} V(t)^{2 / 3}}+\frac{\Delta_{\beta} A_{b}(t)}{2 V(t)}\right] d t
$$

where $D_{s}$ is the absorbed dose contributed from urine content to the bladder wall, $D_{\gamma}$ is the absorbed dose contributed gamma photons, $D_{\beta}$ is the absorbed dose contributed by electrons, $\phi_{\gamma}$ is the dose conversion factor from the contribution of gamma photos $\left(\phi_{\gamma}=404.71 \mathrm{~cm}^{2} \cdot \mu G y /(\mathrm{MBq} \cdot \min )\right)$ and $\Delta_{\beta}$ is mean electron particle energy emitted per nuclear transition of the radionuclide $\left(\Delta_{\beta}=2.3 \times 10^{3} \mathrm{~g} \cdot \mu G y /(M B q \cdot \min )\right)[20]$.

In this study, we assumed that the urine increases at the same rate between two successive voids:

$$
V(t)=\left\{\begin{array}{c}
V_{0}+\int u(t) d t ; 0 \leq t<T_{1} \\
V_{b}\left(t_{i}\right)+\int u(t) d t ; T_{n-1} \leq t<T_{n}
\end{array}\right.
$$

where $u(t)$ represents urine production rate.

For dynamic model considering two voiding, absorbed dose after second voiding was assumed to be zero.

Organ absorbed dose calculation. In order to make a comparison of changes of effective dose using different measurement methods, it is necessary to calculate the organ absorbed dose to estimate the effective dose. The calculation of the dose was made via MIRD method as follows[27, 28]:

$$
\frac{D_{r k}}{A_{0}}=\sum \frac{\widetilde{A_{l}}}{A_{0}} S\left(r_{k} \leftarrow r_{h}\right)=\sum \tau_{l} S\left(r_{k} \leftarrow r_{h}\right)
$$

where $D_{r k}$ is the absorbed dose to a target organ, $S\left(r_{k} \leftarrow r_{h}\right)$ is the mean absorbed dose to a target region per unit cumulated activity in a source region, $r_{k}$ is the target organ, $r_{h}$ is the source organ, and $\tau$ is residence time.

$S$ value calculation. ICRP reference phantom is widely used in absorbed dose estimation[29]. However, the phantom was not based on the size of Chinese people. We revised the ICRP realistic reference phantom into two special phantoms for a man (height:170 cm; weight:60 kg) and a woman (height:160 cm; weight: $51 \mathrm{~kg}$ ) based on two subjects to carry out the Monte-Carlo simulation.

\section{Results}

Comparison of cumulated time activity. Spline method and multi-exponential method were adapted in this study to fit the time 
activity curve of source organs including brain, heart, kidneys, lungs and liver in each subject. FIGURE.2 shows the comparison between traditionally multi-exponential methods and spline method used in this study.
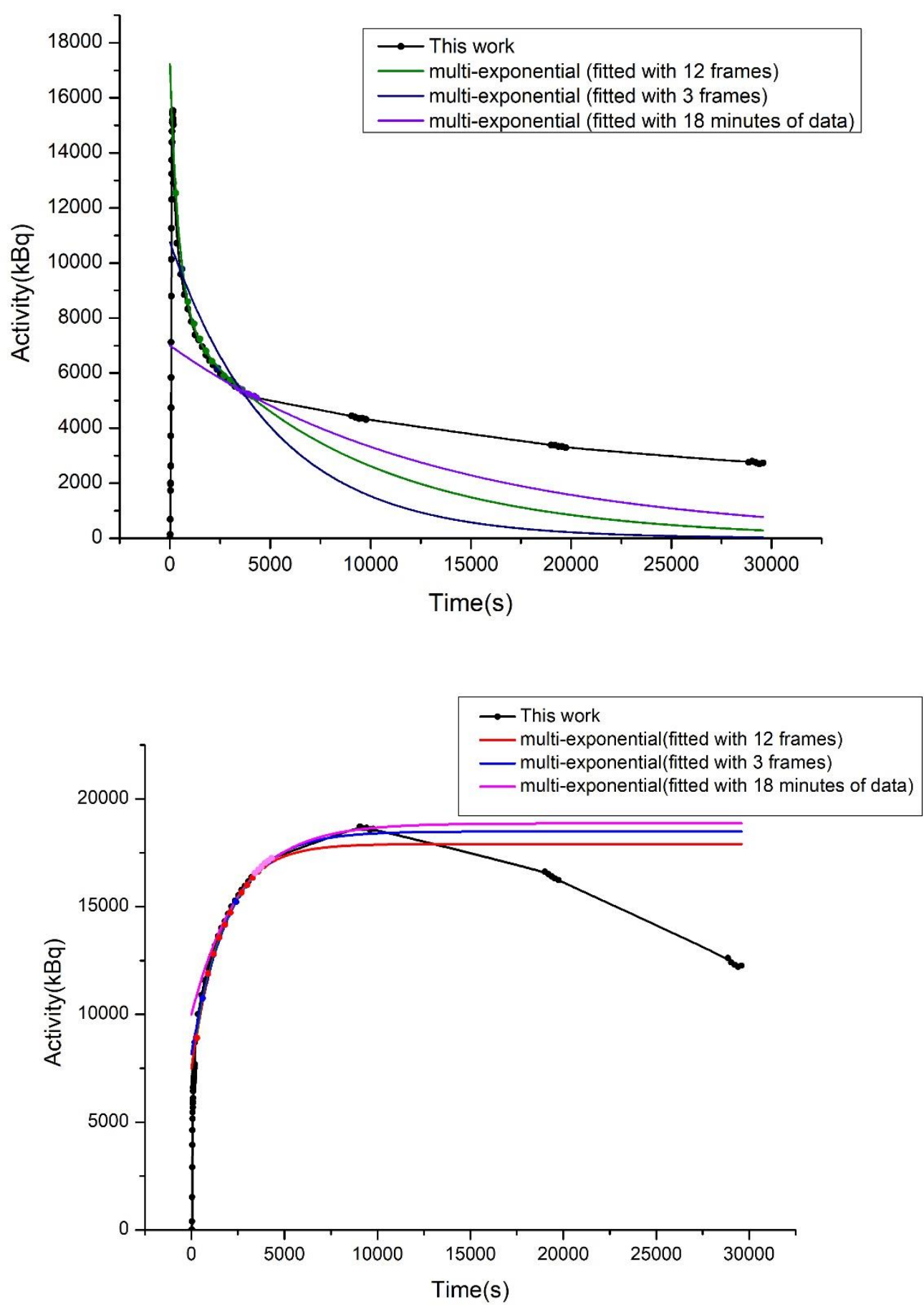

FIGURE.2. A comparison between multi-exponential method with $12 * 120 \mathrm{~s}, 3 * 180 \mathrm{~s}$ and 18 minutes of data and spline method ( 8 hours) in liver data(left) and brain data(right) fitting in one of the studies (decay corrected).

FIGURE. 2 shows the differences of fitting result of TACs for spline method and multi-exponential method with $12 * 120$ s and $3 * 180$ s data with different assumptions as described in previous studies along with multi-exponential method with 18 minutes of data at one hour after injection. Some studies assumed that only physical decay matters after the last scan, while some didn't. The differences in cumulated activity was produced by the short measuring time and traditional fitting method in two periods, the first minute after injection and 3 hours after injection.

TABLE 1. Average residence time and standard deviation calculated using spline method and multi-exponential methods. 


\begin{tabular}{|c|c|c|c|c|c|c|}
\hline Organ & $\begin{array}{l}\text { Spline } \\
\text { method }\end{array}$ & $\begin{array}{l}\text { Multi- } \\
\text { exponential } \\
\text { method } 12 \\
\text { frames }\end{array}$ & $\begin{array}{l}\text { Multi-exponential } \\
\text { method } 12 \text { frames } \\
\text { (only physical decay } \\
\text { after } 60 \text { minutes) }\end{array}$ & $\begin{array}{c}\text { Multi- } \\
\text { exponential } \\
\text { method } 3 \text { frames }\end{array}$ & $\begin{array}{l}\text { Multi-exponential } \\
\text { method } 3 \text { frames } \\
\text { (only physical decay } \\
\text { after } 70 \text { minutes) }\end{array}$ & $\begin{array}{c}\text { Multi- } \\
\text { exponential with } \\
18 \text { minutes of } \\
\text { data }\end{array}$ \\
\hline Brain & $0.391 \pm 0.066$ & $0.377 \pm 0.073 *$ & $0.358 \pm 0.071 * *$ & $0.380 \pm 0.067 *$ & $0.354 \pm 0.065 * * *$ & $0.370 \pm 0.073 * *$ \\
\hline Heart & $0.041 \pm 0.022$ & $0.044 \pm 0.021$ & $0.039 \pm 0.019$ & $0.040 \pm 0.023$ & $0.036 \pm 0.018$ & $0.044 \pm 0.038$ \\
\hline Liver & $0.117 \pm 0.025$ & $0.099 \pm 0.015^{* * *}$ & $0.136 \pm 0.021 * * *$ & $0.086 \pm 0.013 * * *$ & $0.135 \pm 0.021 * * *$ & $0.101 \pm 0.023 *$ \\
\hline Lungs & $0.058 \pm 0.030$ & $0.062 \pm 0.038$ & $0.071 \pm 0.038 * * *$ & $0.049 \pm 0.022$ & $0.072 \pm 0.032 * *$ & $0.057 \pm 0.030$ \\
\hline Kidneys & $0.033 \pm 0.009$ & $0.032 \pm 0.011$ & $0.041 \pm 0.012 * * *$ & $0.025 \pm 0.008 * * *$ & $0.040 \pm 0.013 * * *$ & $0.028 \pm 0.033$ * \\
\hline \multicolumn{7}{|c|}{ Data are mean \pm standard deviation for each study. } \\
\hline
\end{tabular}

Compared with estimation using methods based on previous studies, it is obvious that the scarcer the data is, the larger differences were introduced (TABLE.1). The multi-exponential methods could bring significant differences in residence time for liver under every circumstance (18.38\% on average). However, the differences brought by estimation method was neglectable compared with individual variation for myocardium. Assuming the activity only decreases by physical decay after the last scan could bring significant differences in cumulated activity no matter how scarce the data is when it comes to brain, liver, lungs and kidneys (8.95\%, $15.82 \%, 23.14 \%$ and $22.73 \%$ on average). For organs other than liver, multi-exponential method was good enough to give an estimation of residence time, therefore cumulated activity, based on 12 frames of data covering the first hour after injection and considering biological decay after last scan (less than $6.89 \%$ differences). The residence time of the studies where only physical decay matters after 60 to 80 minutes could be biased based on Table 1, especially considering a series of scarce data (three frames).

When considering using 18 minutes of data (imitating clinical situation) to estimate the dose, the average differences of residence time of spline method and estimation using only 18 minutes of data of brain, heart, kidney, liver and lungs are $8.38 \%$, $15.13 \%$, $25.02 \%, 23.94 \%$ and $16.50 \%$. However, using the $6 * 180$ s frames of data required a manual filtering to make sure the data point with visual error was excluded, which makes this mothed somehow challenging.

\section{Comparison of bladder wall dose}

The absorbed dose of the bladder wall can be divided into two part, the dose caused by the bladder content and the dose caused by other organs. The absorbed dose of the bladder wall caused by the bladder content can be calculated using the dynamic model which is a function of volume and activity of the bladder content (FIGURE.3). To clarify the differences brought by long time measurement and short time measurement of bladder dose, we compared 8 hours dynamic model and a dynamic model only considering two voiding. Dynamic model considering the voiding within 8 hours after the injection have the exact same parameters and assumptions as previous dynamic models except for the duration of measurement $[18,17]$. 


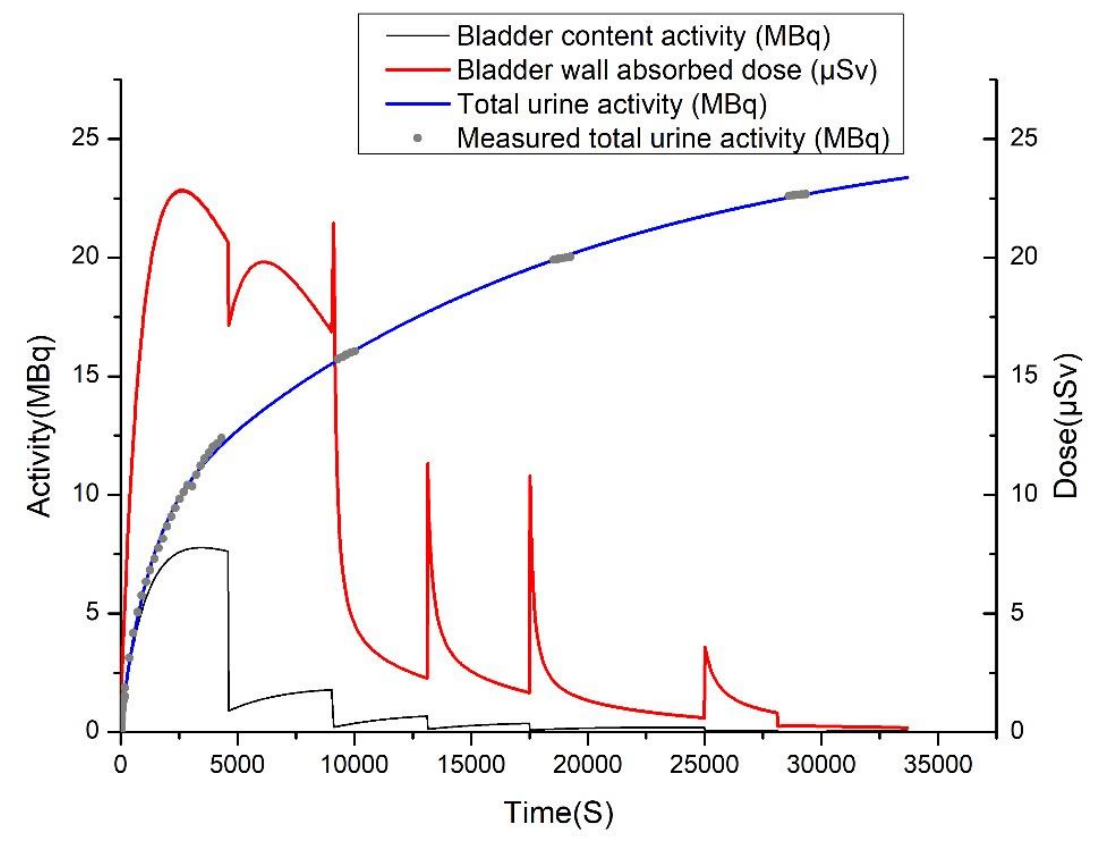

FIGURE.3. Representative time activity curve of bladder content (not decay corrected), fitting total urine activity and measured total urine activity (including bladder urine and excreted urine, decay corrected) and absorbed dose to the bladder wall.

Bladder dose caused by bladder content per activity of dynamic model using 8 hours model and the two-voiding dynamic model are 58.63 \pm 23.95 and $52.69 \pm 23.56 \mu \mathrm{Gy} / \mathrm{MBq}$. Bladder dose from 8-hours dynamic model was significantly larger than that of two voiding by $13.79 \%$ ( $\mathrm{p}=0.0005$ for paired $\mathrm{t}$-test). The assumption that the absorbed dose after the first two voiding was zero could underestimate $1.6 \%$ to $28.2 \%$ of absorbed dose. Based on the dynamic model, it is obvious that the absorbed dose to the bladder per injected activity is related to the initial volume of bladder content when the intravenous injection began, urine production rate and the time of first urine excretion.

Multivariate regression shows that all these factors are significantly related to the urine bladder wall absorbed dose per injection activity (TABLE.2) considering both dynamic models.

TABLE. 2. Urinary bladder wall absorbed dose per injected activity multivariate regression.

\begin{tabular}{|c|c|c|c|c|c|c|}
\hline $\ln (B)$ & $\begin{array}{c}\text { Coef. } \\
\text { (8 hours) }\end{array}$ & $\begin{array}{c}\text { Standard } \\
\text { error }\end{array}$ & $\mathbf{P}>|t|$ & $\begin{array}{c}\text { Coef. } \\
\text { (two voiding) }\end{array}$ & $\begin{array}{c}\text { Standard } \\
\text { error }\end{array}$ & $\mathbf{P}>|t|$ \\
\hline $\ln (F)$ & 0.903 & 0.017 & 0.000 & 0.871 & 0.020 & 0.000 \\
\hline $\ln (I)$ & -0.055 & 0.013 & 0.004 & -0.061 & 0.015 & 0.006 \\
\hline $\ln (\mathbf{U})$ & -0.752 & 0.195 & 0.002 & -0.730 & 0.190 & 0.006 \\
\hline
\end{tabular}

$\mathrm{B}$ is the bladder wall absorbed dose per injected activity ( $\mu \mathrm{Gy} / \mathrm{MBq}), \mathrm{F}$ is the first voiding time (min), $\mathrm{I}$ is the initial volume of bladder $(\mathrm{mL})$ and $\mathrm{U}$ is the urine production rate $(\mathrm{mL} / \mathrm{min})$. The result shows that urinary bladder wall absorbed dose per injected activity is positively related to the first voiding time and negatively related to the initial bladder content volume and urine production rate. The absorbed dose of bladder wall per injected activity could be expressed as when considering voiding in 8 hours after injection:

$$
B=\frac{F^{0.903}}{I^{0.055} U^{0.752}}
$$

The absorbed dose of bladder wall per injected activity could be expressed as when considering two voiding:

$$
B=\frac{F^{0.871}}{I^{0.061} U^{0.752}}
$$


When considering different dynamic model, the correlation the between the absorbed dose and urinary characteristic differs. If only two voiding is considered, the initial volume of bladder effects the bladder wall dose more than 8 hours dynamic method, with the first voiding time on the contrary.

\section{Comparison of absorbed dose and effective dose}

None of the whole-body internal dosimetry study so far has adapted a dynamic bladder model. It remains unclear which factor changes the estimation of effective dose more, the choice of model or the duration of measurement. Also, the residence time estimation method could make a difference in cumulated activity. It is necessary to find out whether this method makes a significant difference in effective dose estimation.

The absorbed dose of most target organs except the bladder wall was calculated using S-value obtained from Monte-Carlo simulation. A series of S-value for male and female Asian-based revised phantom along with the absorbed dose of each organ are presented in Appendix B and C. The tissue weighting factor was based on ICRP 103 publication [30]. The absorbed dose of bladder wall caused by other organs was calculated using S-value obtained from Monte-Carlo simulation. Among all the organs, bladder wall and brain received the highest absorbed dose of $1.24 \mathrm{E}-01 \mathrm{mGy} / \mathrm{MBq}$ and $6.82 \mathrm{E}-02 \mathrm{mGy} / \mathrm{MBq}$ respectively, which consisted with literatures.

The effective dose for all subjects was $1.41 \mathrm{E}-02 \pm 1.81 \mathrm{E}-03 \mathrm{mSv} / \mathrm{MBq}$ using spline method and 8 hours dynamic bladder model.

TABLE. 3. effective dose(mSv) estimated using different residence time calculated using different methods.

\begin{tabular}{|c|c|c|c|c|c|}
\hline $\begin{array}{l}\text { Spline } \\
\text { method }\end{array}$ & $\begin{array}{l}\text { Multi- } \\
\text { exponential } \\
\text { method } 12 \\
\text { frames }\end{array}$ & $\begin{array}{l}\text { Multi-exponential } \\
\text { method } 12 \text { frames } \\
\text { (only physical decay } \\
\text { after } 60 \text { minutes) }\end{array}$ & $\begin{array}{c}\text { Multi- } \\
\text { exponential } \\
\text { method } 3 \text { frames }\end{array}$ & $\begin{array}{l}\text { Multi-exponential method } \\
3 \text { frames (only physical } \\
\text { decay after } 70 \text { minutes) }\end{array}$ & $\begin{array}{l}6 * 180 \text { s from } 57 \\
\text { minutes to } 75 \\
\text { minutes }\end{array}$ \\
\hline $\begin{array}{c}1.41 E- \\
02 \pm 1.81 E-03\end{array}$ & $\begin{array}{c}1.41 \mathrm{E}-02 \pm 1.81 \mathrm{E}- \\
03\end{array}$ & $\begin{array}{c}1.28 \mathrm{E}-02 \pm 2.65 \mathrm{E}- \\
03^{* * *}\end{array}$ & $\begin{array}{c}1.35 \mathrm{E}-02 \pm 2.72 \mathrm{E}- \\
03\end{array}$ & $1.27 \mathrm{E}-02 \pm 2.64 \mathrm{E}-03 * * *$ & $\begin{array}{c}1.27 \mathrm{E}-02 \pm 2.66 \mathrm{E}- \\
03 * * *\end{array}$ \\
\hline gnificant & $* *$ sign & nt at $5 \%$ level & nificant at $1 \%$ le & & \\
\hline
\end{tabular}

When using different resident time estimation method with different measurement of TACs, the effective dose could vary significantly. It makes appropriate assumption of the tendency of activity rather than enough data that effect the result of effective dose estimation significantly. A short-time measurement (about 1 hour) can make a significant different estimation of effective dose with the assumption of only physical decay matters after last scan of injection by previous studies[4, 7]. (TABLE.3). The maximum differences between long-time measured spline fitted method and multi-exponential methods with shorter series of data was $9.93 \%$ on average.

TABLE.4. Attribution to effective dose from different source organs.

\begin{tabular}{|c|c|c|c|c|c|c|c|c|}
\hline Source organs & $\begin{array}{l}\text { Remainder } \\
\text { of the body }\end{array}$ & $\begin{array}{l}\text { Bladder } \\
\text { content }\end{array}$ & Brain & Heart & Kidneys & Liver & lungs & $\begin{array}{c}\text { Effective } \\
\text { dose(mSv) }\end{array}$ \\
\hline $\begin{array}{l}\text { Attribution to effective } \\
\text { dose (8 hours) }\end{array}$ & $38.33 \%$ & $21.18 \%$ & $10.86 \%$ & $4.50 \%$ & $3.03 \%$ & $11.67 \%$ & $10.43 \%$ & $1.41 \mathrm{E}-02 \pm 1.81 \mathrm{E}-03$ \\
\hline $\begin{array}{l}\text { Attribution to effective } \\
\text { dose ( } 2 \text { voiding) }\end{array}$ & $38.98 \%$ & $19.80 \%$ & $11.05 \%$ & $4.58 \%$ & $3.08 \%$ & $11.88 \%$ & $10.64 \%$ & $1.39 \mathrm{E}-02 \pm 1.81 \mathrm{E}-03$ \\
\hline
\end{tabular}

Among all the investigated organs, the bladder content contributed the most to the effective dose. When using different types of dynamic bladder model, the bladder content contributed differently to the effective dose (TABLE.4). However, the difference of effective dose was only $1.7 \%$ on average, which is much smaller than deviation introduced by other factors. According to previous studies, the differences of absorbed dose estimation between MIRD and dynamic method contributed $2 \%$ differences to effective dose on average[18], which is only slightly larger than the difference introduce by different dynamic model. A longer bladder dynamic model, compared with two voiding measurement, did not make more differences than the estimation model.

TABLE.5. Comparison of bladder wall dose and effective dose.

\begin{tabular}{cccc}
\hline This work & Deloar et al.[4] & Mejia et al.[3] & ICRP 106[9] \\
\hline
\end{tabular}




\begin{tabular}{lcccc}
\hline $\begin{array}{l}\text { Bladder wall dose } \\
(\mathrm{mGy} / \mathrm{MBq})\end{array}$ & $5.86 \mathrm{E}-02 \pm 2.39 \mathrm{E}-02$ & $3.1 \mathrm{E}-01 \pm 1.8 \mathrm{E}-01$ & $1.2 \mathrm{E}-01$ & $1.3 \mathrm{E}-01$ \\
$\begin{array}{l}\text { Effective dose } \\
(\mathrm{mSv} / \mathrm{MBq})\end{array}$ & $1.41 \mathrm{E}-02 \pm 1.81 \mathrm{E}-03$ & $2.9 \mathrm{E}-02 \pm 9.2 \mathrm{E}-03$ & $2.4 \mathrm{E}-02$ & $1.9 \mathrm{E}-02$ \\
\hline
\end{tabular}

TABLE. 5 shows that $50.19 \%$ of difference of effective dose was contributed by the difference bladder wall dose on average. It is obvious that the dynamic method helped to make an estimation much smaller than previous studies. A smaller residence time along with a dynamic model contributed to make a difference. It is obvious that when using a dynamic long-time measured TACs, considering more times of voiding helped to make a smaller estimation of the absorbed dose of bladder. A more accurate measurement of cumulated activity is more important than dose estimation model. The bladder wall dose was at least $51.17 \%$, smaller than previous study using fixed bladder content volume in TABLE.5.

\section{Discussion}

As far as we knew, almost of the studies either performed a single PET procedure for less than 80 minutes [2-4] or perform multiple PET scans at a rather long interval [7]. Even considering the organs where the cumulated activity estimation methods makes a significance difference, however, it makes no significant differences in effective dose estimation if with appropriate assumption. A short-time measurement can still make a satisfying estimation if there are enough amount of data and the assumption was appropriate, even considering only 18 minutes of clinical data.

TABLE 6. residence time (standardized cumulated activity), in hours, used for absorbed dose estimation.

\begin{tabular}{|c|c|c|c|c|c|c|c|}
\hline \multicolumn{8}{|c|}{ Data source } \\
\hline Organ & This work & $\begin{array}{c}\text { Deloar et al. } \\
{[4]}\end{array}$ & $\begin{array}{l}\text { Hays and } \\
\text { Segall[5] }\end{array}$ & $\begin{array}{c}\text { Kaushik et } \\
\text { al.[8] }\end{array}$ & $\begin{array}{c}\text { Mejia et al. } \\
\text { [3] }\end{array}$ & $\begin{array}{c}\text { Niven at al. } \\
\text { [6] }\end{array}$ & ICRP 106[9] \\
\hline Brain & $0.391 \pm 0.066$ & $0.230 \pm 0.040$ & $0.245 \pm 0.090$ & $0.193 \pm 0.040$ & $0.178 \pm 0.041$ & $0.243 \pm 0.029$ & 0.21 \\
\hline Heart & $\begin{array}{c}0.041 \pm 0.022 \\
* *\end{array}$ & $\begin{array}{c}\mathbf{0 . 0 2 5} \pm 0.001 \\
* *\end{array}$ & $0.133 \pm 0.065$ & & $0.085 \pm 0.020$ & & 0.11 \\
\hline Liver & $0.117 \pm 0.025$ & $0.084 \pm 0.016$ & $0.161 \pm 0.057$ & $0.108 \pm 0.038$ & $0.112 \pm 0.029$ & & 0.13 \\
\hline Lungs & $0.058 \pm 0.030$ & $0.055 \pm 0.008$ & $0.084 \pm 0.028$ & & $0.023 \pm 0.003$ & & 0.079 \\
\hline Kidneys & $0.033 \pm 0.009$ & $0.036 \pm 0.019$ & & & $0.034 \pm 0.009$ & & \\
\hline Bladder & $0.124 \pm 0.032$ & $0.151 \pm 0.039$ & * & & & & 0.26 \\
\hline Remainder & $1.623 \pm 0.139$ & $1.975 \pm 0.097$ & $1.790 \pm 0.139$ & & & & 1.7 \\
\hline \multicolumn{8}{|c|}{$* 0.101 \pm 0.041,0.119 \pm 0.047$ and $0.191 \pm 0.075$ for excretion at 120,144 and $288 \mathrm{~min}$, and $0.040 \pm 0.017$ for voiding at 30,60 and 120 , then every $120 \mathrm{~min}$} \\
\hline \multicolumn{8}{|c|}{ Data are mean \pm standard deviation for each study } \\
\hline Residual time fo & rine that decay 0 & ide the body : & \pm 0.053 & & & & \\
\hline
\end{tabular}

Besides the differences brought by different methods and measurement time, the residence time could vary significant from individuals. The differences of residence time of this work and previous studies partially resulted from these two aspects. The estimated residence time of brain in this work was significantly higher than these values in previous studies [3-6, 8]. The cumulated activity of other organs was between the reported maximum level and minimum level while significant divergences of bladder residence time could be seen in TABLE.7 because of different voiding models. Compared with previous studies, long time measurement did not observe a significant difference in residence time for kidneys, lung, liver and heart.

Furthermore, all the subjects in this work have a normal Body Mass Index (male: $22.81 \pm 2.79$, female: $23.85 \pm 3.21$ ), and we also used an Asian-based revised phantom to estimate S-value and Chinese subjects to estimate the cumulated activity. Translating this result into estimating the effective dose of different types of people needs further verification.

In spite of the increase in absorbed dose of bladder when using a long-time measurement, it contributed very little when estimating the effective dose, so did different bladder models. However, previous studies often overestimate the cumulated activity of urinary 
bladder for underestimating the activity of the urine excreted out of the body.

Multivariate regression result shows that the absorbed dose in bladder wall was mostly related to the urine time rather than initial urine volume at injection time and urine production rate. The results consist with the result by Wu et al. However, translating this result into estimating the absorbed dose when the voiding time is shorter than 75 minutes could be inaccurate, especially about 50 minutes after injection[18].

Conclusion By using the total-body PET/CT scanner, we measured multi organs time-activity curves in 8 hours at same time window to develop a new method to estimate organ cumulated activity and organ dose. A short-time measurement can make a significant different estimation of effective dose with specific assumption. However, using only 18 minutes of data at one hour after injection could make an estimation of effective dose $9.9 \%$ smaller than the result of a long-time estimation on average, which indicates that the data of clinical procedure could be used for large scale retrospective dose survey. In spite of a significant increase in bladder wall dose, a long-time dynamic bladder dose model makes little difference in effective dose estimation. However, when considering the absorbed dose of bladder wall, a long-time dynamic model could give a significant different dose estimation compared with a short time model.

\section{References}

1. Fletcher JW, Djulbegovic B, Soares H, Siegel BA, Lowe V, Lyman G et al. Recommendations on the use of F-18-FDG PET in oncology. Journal Of Nuclear Medicine. 2008;49(3):480-508. doi:10.2967/jnumed.107.047787.

2. Jones SC, Alavi A, Christman D, Montanez I, Wolf AP, Reivich M. The radiation dosimetry of 2 [F18]fluoro-2-deoxy-D-glucose in man. J Nucl Med. 1982;23(7):613-7.

3. Mejia AA, Nakamura T, Masatoshi I, Hatazawa J, Masaki M, Watanuki S. Estimation of absorbed doses in humans due to intravenous administration of fluorine-18-fluorodeoxyglucose in PET studies. Journal of nuclear medicine : official publication, Society of Nuclear Medicine. 1991;32(4):699.

4. Deloar HM, Fujiwara T, Shidahara M, Nakamura T, Watabe H, Narita $Y$ et al. Estimation of absorbed dose for 2-[F-18]fluoro-2-deoxy- d - glucose using whole-body positron emission tomography and magnetic resonance imaging. European Journal of Nuclear Medicine. 1998;25(6):565-74. doi:10.1007/s002590050257.

5. Hays MT, Segall GM. A mathematical model for the distribution of fluorodeoxyglucose in humans. J Nucl Med. 1999;40(8):1358-66.

6. Niven E, Thompson M, Nahmias C. Absorbed dose to the adult male and female brain from F-18fluorodeoxyglucose. Health Physics. 2001;80(1):62-6.

7. Khamwan K, Krisanachinda A, Pasawang P. The determination of patient dose from 18 F-FDG PET/CT examination. Radiation Protection Dosimetry. 2010;141(1):50-5. doi:10.1093/rpd/ncq140.

8. Kaushik A, Jaimini A, Tripathi M, D'Souza M, Sharma R, Mondal A et al. Estimation of radiation dose to patients from (18) FDG whole body PET/CT investigations using dynamic PET scan protocol. The Indian journal of medical research. 2015;142(6):721-31. doi:10.4103/0971-5916.174563.

9. Icrp. Radiation dose to patients from radiopharmaceuticals. Addendum 3 to ICRP Publication 53. ICRP Publication 106. Approved by the Commission in October 2007. Ann ICRP. 2008;38(1-2):1-197. doi:10.1016/j.icrp.2008.08.003.

10. Quinn B, Dauer Z, Pandit-Taskar N, Schoder H, Dauer LT. Radiation dosimetry of 18F-FDG PET/CT: incorporating exam-specific parameters in dose estimates.(Report). BMC Medical Imaging. 2016;16(1). doi:10.1186/s12880-016-0143-y.

11. Yilmaz G, Tugrul AB, Demir M, Yasar D, Demir B. Assessment of Patient Dose by Positron Emission 
Tomography (PET) and Medical Internal Dose (MIRD) Methods. Acta Physica Polonica A. 2016;130(1):90-2. doi:10.12693/APhysPolA.130.90.

12. Zaman MU, Fatima N, Zaman A, Zaman U, Tahseen R. Significantly Low Effective Dose from 18FDG PET/CT Scans Using Dose Reducing Strategies: "Lesser is Better". Asian Pacific journal of cancer prevention : APJCP. 2016;17(7):3465.

13. Martí-Climent J, Prieto E, Morán V, Sancho L, Rodríguez-Fraile M, Arbizu J et al. Effective dose estimation for oncological and neurological PET/CT procedures. EJNMMI Research. 2017;7(1):1-8. doi:10.1186/s13550-017-0272-5.

14. Paiva FG, Do Carmo Santana P, Mourão AP. Evaluation of patient effective dose in a PET/CT test. Applied Radiation and Isotopes. 2019;145:137-41. doi:10.1016/j.apradiso.2018.12.024.

15. Lee MS, Kim JH, Paeng JC, Kang KW, Jeong JM, Lee DS et al. Whole-Body Voxel-Based Personalized Dosimetry: The Multiple Voxel S-Value Approach for Heterogeneous Media with Nonuniform Activity Distributions. J Nucl Med. 2018;59(7):1133-9. doi:10.2967/jnumed.117.201095.

16. Spielmann V, Li W, Zankl M, Oeh U, Hoeschen C. Uncertainty Quantification in Internal Dose Calculations for Seven Selected Radiopharmaceuticals. The Journal of Nuclear Medicine. 2016;57(1):122. doi:10.2967/jnumed.115.160713.

17. Spielmann V, Li W, Zankl M. Finding sensitive parameters in internal dose calculations for radiopharmaceuticals commonly used in clinical nuclear medicine. Radiation and Environmental Biophysics. 2018;57(3):277-84. doi:10.1007/s00411-018-0750-9.

18. Wu HT, Liu SR, Dong LS, Chung WY, Chou LK, Lee SJ. Dynamic evaluation of absorbed dose to the bladder wall with a balloon-bladder phantom during a study using [18F]fluorodeoxyglucose positron emission imaging. Nucl Med Commun. 2002;23(8):749-55. doi:10.1097/00006231-200208000-00008. 19. Dowd M, Chen CT, Wendel M, Faulhaber P, Cooper MD. RADIATION-DOSE TO THE BLADDER WALL FROM 2-[F-18]FLUORO-2-DEOXY-D-GLUCOSE IN ADULT HUMANS. Journal Of Nuclear Medicine. 1991;32(4):707-12.

20. Wu HT, Liu SR, Lin DY, Chou LK, Chong SN, Lee SJ. Evaluation of the dose to the bladder wall using a dynamic balloon-bladder phantom and TLD measurements in 18F-FDG PET studies. Nucl Med Commun. 1999;20(12):1153-60. doi:10.1097/00006231-199912000-00008.

21. Badawi R, Shi H, Hu P, Chen S, Xu T, Price P et al. First Human Imaging Studies with the EXPLORER Total-Body PET Scanner. The Journal of Nuclear Medicine. 2019;60(3):299. doi:10.2967/jnumed.119.226498.

22. Nichols TE, Jinyi Q, Asma E, Leahy RM. Spatiotemporal reconstruction of list-mode PET data. IEEE Transactions on Medical Imaging. 2002;21(4):396-404. doi:10.1109/TMI.2002.1000263.

23. Quanzheng L, Asma E, Sangtae A, Leahy RM. A Fast Fully 4-D Incremental Gradient Reconstruction Algorithm for List Mode PET Data. IEEE Transactions on Medical Imaging. 2007;26(1):58-67. doi:10.1109/TMI.2006.884208.

24. Verhaeghe J, D' Asseler Y, Vandenberghe S, Staelens S, Lemahieu I. An investigation of temporal regularization techniques for dynamic PET reconstructions using temporal splines. Medical Physics. 2007;34(5):1766-78. doi:10.1118/1.2723879.

25. Powell GF, Chen C-T. Radiation absorbed dose to bladder walls from positron emitters in the bladder content. Medical Physics. 1987;14(6):1079-86. doi:10.1118/1.595988.

26. Thomas SR, Stabin MG, Chen CT, Samaratunga RC. MIRD Pamphlet No. 14 revised: A dynamic urinary bladder model for radiation dose calculations. Task Group of the MIRD Committee, Society of Nuclear Medicine. Journal of nuclear medicine : official publication, Society of Nuclear Medicine. 
1999;40(4):102S.

27. Stabin MG, Tagesson M, Thomas SR, Ljungberg M, Strand SE. Radiation dosimetry in nuclear medicine. Applied radiation and isotopes : including data, instrumentation and methods for use in agriculture, industry and medicine. 1999;50(1):73. doi:10.1016/S0969-8043(98)00023-2.

28. Malamud H. MIRD Primer for Absorbed Dose Calculations. Clinical Nuclear Medicine. 1989;14(9):723-4. doi:10.1097/00003072-198909000-00027.

29. Menzel HG, Clement C, DeLuca P. ICRP Publication 110. Realistic reference phantoms: an ICRP/ICRU joint effort. A report of adult reference computational phantoms. Ann ICRP. 2009;39(2):1-164. doi:10.1016/j.icrp.2009.09.001.

30. Charles M. ICRP Publication 103: Recommendations of the ICRP. Ann ICRP. 2007;37. doi:10.1093/rpd/ncn187.

\section{List of abbreviation}

FOV: Field of View

MIRD: Medical Internal Radiation Dose

PET: Positron emission tomography

TAC: time-activity curve

VOI: Volume of Interest

18F-FDG: 2-[F-18]Fluoro-2-deoxy-D-glucose

\section{Ethics approval and consent to participate}

All procedures performed in studies involving human participants were in accordance with the ethical standards of the institutional and/or national research committee and with the 1964 Helsinki declaration and its later amendments or comparable ethical standards. This research was approved by the Medical Ethics Committee of Zhongshan Hospital, Fudan University and all participants were inform consented.

\section{Consent for publication}

Not applicable.

\section{Availability of data and materials}

The data used in this study are available from the corresponding author on reasonable request.

\section{Competing interests}

The authors have no relevant conflicts of interest to disclose.

\section{Funding}

The National Key Research and Development Program of China (2016YFC0103908), National Natural Science Foundation of China(11475047), Shanghai Science and Technology Project(19DZ1930700), Shanghai Municipal Key Clinical Specialty (shslczdzk03401), National Natural Science Foundation of China,(81701730)

\section{Authors' contributions}


Pengcheng $\mathrm{Hu}$ and Xin Lin were involved in the study design, data analysis and manuscript preparation. Hui Tan and Tianwu Xie helped with data processing. Guobing Liu, Shuguang Chen,Xin Chen and Hao jun Yu helped with image acquisition and processing. Weihai Zhuo helped with the revision of the manuscript. Hongcheng Shi and Haikuan Liu designed the study and contributed to the data analysis and writing of the manuscript. All authors discussed the results and commented on the manuscript.

\section{Supplemental Data}

bladder dose caused by bladder content per activity of dynamic model using different methods and other urinary characteristics.

\begin{tabular}{ccccc}
\hline $\begin{array}{c}\text { Bladder dose per } \\
\text { activity (8 hours) } \\
(\mu \mathrm{Gy} / \mathrm{MBq})\end{array}$ & $\begin{array}{c}\text { Bladder dose per } \\
\text { activity (two voiding) }\end{array}$ & $\begin{array}{c}\text { First voiding time } \\
(\mu \mathrm{Gy} / \mathrm{MBq})\end{array}$ & $\begin{array}{c}\text { (minute) } \\
\text { Initial bladder } \\
\text { volume(mL) }\end{array}$ & $\begin{array}{c}\text { Urine production } \\
\text { rate }(\mathrm{mL} / \mathrm{min})\end{array}$ \\
\hline 77.42 & 65.11 & 87 & 70.00 & 0.632 \\
51.27 & 41.98 & 85 & 63.64 & 0.839 \\
81.91 & 80.99 & 94 & 0.00 & 1.064 \\
60.60 & 54.77 & 87 & 0.00 & 1.782 \\
46.44 & 36.84 & 85 & 0.00 & 2.294 \\
23.86 & 21.00 & 88 & 63.18 & 1.941 \\
106.85 & 103.02 & 88 & 0.00 & 1.022 \\
50.92 & 50.14 & 128 & 0.00 & 3.125 \\
45.54 & 40.71 & 83 & 117.55 & 1.354 \\
\hline
\end{tabular}

Appendix A

\begin{tabular}{|c|c|c|c|c|c|c|c|c|}
\hline \multirow[b]{2}{*}{ Target organ } & \multicolumn{7}{|c|}{ Male S-value $\left(\mathrm{mGy} /\left(\mathrm{MBq}^{*} \mathrm{~h}\right)\right)$} & \multirow[b]{2}{*}{$\begin{array}{c}\text { Absorbed dose } \\
\text { (mGy/MBq) }\end{array}$} \\
\hline & $\begin{array}{l}\text { Remainder } \\
\text { of the body }\end{array}$ & $\begin{array}{l}\text { Bladder } \\
\text { content }\end{array}$ & Brain & Heart* & Kidneys & Liver & Lungs & \\
\hline Skin & $2.71 \mathrm{E}-03$ & $1.79 E-03$ & 2.14E-03 & $1.79 E-03$ & $2.05 E-03$ & $1.98 E-03$ & 2.03E-03 & $5.95 E-03 \pm 2.09 E-04$ \\
\hline Adipose tissue & 4.12E-03 & 7.27E-03 & $1.66 E-03$ & 4.22E-03 & $6.54 E-03$ & 4.09E-03 & 4.09E-03 & $9.35 E-03 \pm 2.41 E-04$ \\
\hline Muscle & $1.00 \mathrm{E}-02$ & $3.45 \mathrm{E}-03$ & 6.95E-04 & $1.85 E-03$ & $2.65 \mathrm{E}-03$ & $1.91 \mathrm{E}-03$ & $2.50 \mathrm{E}-03$ & $1.76 \mathrm{E}-02 \pm 1.22 \mathrm{E}-03$ \\
\hline Adrenals & 2.15E-03 & $5.60 \mathrm{E}-04$ & 1.07E-04 & $6.94 E-03$ & 7.03E-02 & 2.00E-02 & $5.47 \mathrm{E}-03$ & $8.81 E-03 \pm 7.74 E-04$ \\
\hline Bladder wall & $3.72 \mathrm{E}-03$ & $1.87 E-01 \triangle$ & $2.56 \mathrm{E}-06$ & 2.17E-04 & 1.13E-03 & $5.80 \mathrm{E}-04$ & $1.89 \mathrm{E}-04$ & 6. $81 \mathrm{E}-01 \pm 2.79 \mathrm{E}-02$ \\
\hline Blood vessel & $9.46 \mathrm{E}-03$ & $1.37 \mathrm{E}-02$ & $7.36 \mathrm{E}-04$ & 4.59E-02 & 2.91E-02 & 2.31E-02 & $2.78 \mathrm{E}-02$ & $2.49 \mathrm{E}-02 \pm 1.37 \mathrm{E}-03$ \\
\hline Brain & $5.65 \mathrm{E}-04$ & $3.71 \mathrm{E}-06$ & $1.66 \mathrm{E}-01$ & 2.93E-04 & $6.43 E-05$ & $1.46 \mathrm{E}-04$ & 4.51E-04 & $6.21 \mathrm{E}-02 \pm 1.13 \mathrm{E}-02$ \\
\hline Breasts & $1.45 E-03$ & $1.66 \mathrm{E}-04$ & 3.21E-04 & 9.93E-03 & $2.09 E-03$ & $7.02 E-03$ & 8.41E-03 & $4.41 \mathrm{E}-03 \pm 4.30 \mathrm{E}-04$ \\
\hline Bronchi & 5.13E-03 & 3.82E-04 & $1.24 \mathrm{E}-03$ & 9.02E-02 & $6.80 E-03$ & 1.83E-02 & $1.08 E-01$ & $2.26 \mathrm{E}-02 \pm 4.02 \mathrm{E}-03$ \\
\hline Esophagus & $1.95 E-03$ & $1.22 \mathrm{E}-04$ & $9.67 E-04$ & 3.73E-02 & $3.75 E-03$ & 8.40E-03 & $1.57 \mathrm{E}-02$ & $7.42 E-03 \pm 1.07 E-03$ \\
\hline Eye balls & 6.98E-04 & $6.70 \mathrm{E}-06$ & $1.58 \mathrm{E}-02$ & 4.74E-04 & 1.01E-04 & 2.29E-04 & 5.57E-04 & $7.06 \mathrm{E}-03 \pm 1.03 \mathrm{E}-03$ \\
\hline Eye lens & $6.58 \mathrm{E}-04$ & $1.05 E-15$ & 1.11E-02 & 4.13E-04 & $1.29 \mathrm{E}-05$ & $6.12 E-05$ & $5.22 \mathrm{E}-04$ & $5.23 \mathrm{E}-03 \pm 7.12 \mathrm{E}-04$ \\
\hline $\begin{array}{c}\text { Gall Bladder } \\
\text { wall }\end{array}$ & $2.64 \mathrm{E}-03$ & $1.44 \mathrm{E}-03$ & $1.95 E-04$ & $1.06 \mathrm{E}-02$ & $2.81 E-02$ & 8.35E-02 & $7.85 E-03$ & $1.62 \mathrm{E}-02 \pm 2.50 \mathrm{E}-03$ \\
\hline Heart wall & $1.40 E-03$ & $1.67 \mathrm{E}-04$ & 2.73E-04 & 4.62E-01 & $3.31 \mathrm{E}-03$ & 8.38E-03 & $1.74 \mathrm{E}-02$ & $2.61 \mathrm{E}-02 \pm 1.09 \mathrm{E}-02$ \\
\hline Kidney & $2.24 \mathrm{E}-03$ & $9.65 \mathrm{E}-04$ & $6.94 \mathrm{E}-05$ & $3.69 \mathrm{E}-03$ & $5.94 \mathrm{E}-01$ & $1.22 \mathrm{E}-02$ & 2.91E-03 & $2.39 \mathrm{E}-02 \pm 6.10 \mathrm{E}-03$ \\
\hline Larynx & $1.83 \mathrm{E}-03$ & 8.28E-06 & $1.88 E-02$ & $1.29 \mathrm{E}-03$ & $1.73 E-04$ & 4.46E-04 & $1.71 E-03$ & $1.02 E-02 \pm 1.16 E-03$ \\
\hline
\end{tabular}




\begin{tabular}{|c|c|c|c|c|c|c|c|c|}
\hline LI wall & $2.55 E-03$ & $9.95 E-03$ & $4.40 \mathrm{E}-05$ & $2.49 \mathrm{E}-03$ & $1.06 \mathrm{E}-02$ & $6.89 \mathrm{E}-03$ & $1.74 \mathrm{E}-03$ & $6.72 E-03 \pm 2.49 E-04$ \\
\hline Liver & $1.87 E-03$ & 5.54E-04 & $1.70 \mathrm{E}-04$ & $1.09 \mathrm{E}-02$ & $1.44 \mathrm{E}-02$ & $1.53 E-01$ & $9.51 E-03$ & $2.27 E-02 \pm 4.61 E-03$ \\
\hline Lung & 2.13E-03 & $1.38 E-04$ & 4.64E-04 & $1.98 \mathrm{E}-02$ & $3.05 E-03$ & $8.41 E-03$ & $1.52 \mathrm{E}-01$ & $1.59 \mathrm{E}-02 \pm 4.89 \mathrm{E}-03$ \\
\hline Lymph node & $1.61 \mathrm{E}-03$ & $5.92 \mathrm{E}-03$ & 4.04E-04 & $7.56 \mathrm{E}-03$ & $3.46 \mathrm{E}-03$ & $3.20 \mathrm{E}-03$ & $4.55 E-03$ & $4.62 E-03 \pm 1.87 E-04$ \\
\hline $\begin{array}{c}\text { Oral cavity } \\
\text { layer }\end{array}$ & $5.83 E-03$ & 4.72E-05 & 3.44E-02 & $3.90 \mathrm{E}-03$ & $5.62 E-04$ & $1.74 E-03$ & $4.52 \mathrm{E}-03$ & $2.29 \mathrm{E}-02 \pm 1.99 \mathrm{E}-03$ \\
\hline Pancreas & $1.65 E-03$ & 1.10E-03 & 7.79E-05 & 7.32E-03 & $1.93 E-02$ & 2.30E-02 & 4.01E-03 & $6.75 E-03 \pm 7.03 E-04$ \\
\hline Pituitary & $1.14 E-03$ & 2.01E-15 & $6.54 \mathrm{E}-02$ & 6.19E-04 & $3.34 \mathrm{E}-05$ & 3.39E-05 & 7.36E-04 & $2.60 \mathrm{E}-02 \pm 4.36 \mathrm{E}-03$ \\
\hline \multicolumn{9}{|l|}{ Gland } \\
\hline Salivary Gland & $1.83 E-03$ & 1.03E-05 & $9.65 E-03$ & $1.05 E-03$ & $1.94 E-04$ & 4.42E-04 & $1.55 \mathrm{E}-03$ & $6.76 \mathrm{E}-03 \pm 5.49 \mathrm{E}-04$ \\
\hline SI wall & $1.68 E-03$ & 8.35E-03 & 2.17E-05 & $1.48 \mathrm{E}-03$ & $7.36 \mathrm{E}-03$ & 3.08E-03 & 9.46E-04 & $4.47 E-03 \pm 1.82 E-04$ \\
\hline Bone surface & $3.24 E-03$ & 3.62E-03 & $5.62 \mathrm{E}-03$ & $2.98 E-03$ & $2.66 \mathrm{E}-03$ & 2.38E-03 & 4.29E-03 & $8.58 E-03 \pm 2.33 E-04$ \\
\hline Bone marrow & $7.75 E-03$ & 1.15E-02 & 8.75E-03 & $7.42 \mathrm{E}-03$ & $7.60 \mathrm{E}-03$ & 6.52E-03 & 8.94E-03 & $1.92 E-02 \pm 3.79 E-04$ \\
\hline Bone cartilage & 6.06E-04 & $1.45 \mathrm{E}-03$ & $1.46 \mathrm{E}-04$ & 5.71E-04 & 7.89E-04 & 4.53E-04 & 4.79E-04 & $1.35 E-03 \pm 3.94 E-05$ \\
\hline Spinal cord & $3.20 \mathrm{E}-03$ & 2.83E-04 & 4.52E-03 & $1.02 E-02$ & $7.92 E-03$ & $6.76 \mathrm{E}-03$ & 1.16E-02 & $9.21 E-03 \pm 3.90 E-04$ \\
\hline Spleen & 2.28E-03 & 3.79E-04 & 1.69E-04 & 1.13E-02 & $1.96 \mathrm{E}-02$ & 4.14E-03 & 1.17E-02 & $6.23 E-03 \pm 3.47 E-04$ \\
\hline Stomach wall & $1.74 \mathrm{E}-03$ & 6.06E-04 & 1.12E-04 & 2.03E-02 & 1.01E-02 & $1.46 \mathrm{E}-02$ & $7.41 \mathrm{E}-03$ & $6.40 \mathrm{E}-03 \pm 7.28 \mathrm{E}-04$ \\
\hline Thymus & $1.60 \mathrm{E}-03$ & 2.98E-05 & $7.42 \mathrm{E}-04$ & $1.90 \mathrm{E}-02$ & $7.85 E-04$ & 2.38E-03 & 1.47E-02 & $5.05 E-03 \pm 6.21 E-04$ \\
\hline Thyroid & 3.13E-03 & $4.81 \mathrm{E}-05$ & 2.17E-03 & $8.16 E-03$ & $6.97 E-04$ & 1.69E-03 & 1.11E-02 & $7.25 E-03 \pm 3.87 E-04$ \\
\hline Tongue & $1.24 \mathrm{E}-03$ & $1.06 E-05$ & $5.90 \mathrm{E}-03$ & 8.04E-04 & 1.09E-04 & 3.30E-04 & $1.02 E-03$ & $4.35 \mathrm{E}-03 \pm 3.32 \mathrm{E}-04$ \\
\hline Tonsil & $1.74 E-03$ & $1.50 \mathrm{E}-06$ & 2.24E-02 & $5.62 \mathrm{E}-04$ & $1.06 \mathrm{E}-04$ & 2.31E-04 & $6.90 \mathrm{E}-04$ & $1.12 E-02 \pm 1.41 E-03$ \\
\hline Trachea & $2.47 E-03$ & 2.88E-05 & $1.68 \mathrm{E}-03$ & $1.52 \mathrm{E}-02$ & $1.21 E-03$ & 2.44E-03 & 1.63E-02 & $6.78 E-03 \pm 5.75 E-04$ \\
\hline Ureter & $3.29 \mathrm{E}-03$ & $1.95 \mathrm{E}-02$ & $2.46 \mathrm{E}-05$ & $1.92 E-03$ & 2.09E-02 & 4.77E-03 & 1.27E-03 & $9.09 E-03 \pm 4.73 E-04$ \\
\hline Testis & $2.65 E-03$ & 4.00E-03 & 7.31E-07 & $1.95 \mathrm{E}-05$ & $9.26 \mathrm{E}-05$ & $6.45 \mathrm{E}-05$ & $1.25 \mathrm{E}-05$ & $4.81 E-03 \pm 2.99 E-04$ \\
\hline Prostate & $5.90 \mathrm{E}-03$ & 1.07E-01 & $2.06 \mathrm{E}-06$ & $1.38 E-04$ & 8.36E-04 & 3.85E-04 & 1.11E-04 & $2.24 \mathrm{E}-02 \pm 2.53 \mathrm{E}-03$ \\
\hline
\end{tabular}

*left ventricle only $\triangle$ the value is not used in the calculation, but just for reference.

Appendix B

\begin{tabular}{|c|c|c|c|c|c|c|c|c|}
\hline \multirow[b]{2}{*}{ Target organ } & \multicolumn{7}{|c|}{ Female S-value (mGy/(MBq*h)) } & \multirow[b]{2}{*}{$\begin{array}{l}\text { Absorbed dose } \\
\text { (mGy/MBq) }\end{array}$} \\
\hline & $\begin{array}{l}\text { Remainder } \\
\text { of the body }\end{array}$ & $\begin{array}{l}\text { Bladder } \\
\text { content }\end{array}$ & Brain & Heart* & Kidneys & Liver & Lungs & \\
\hline Skin & 2.90E-03 & $2.35 E-03$ & $1.96 E-03$ & 2.31E-03 & 2.25E-03 & 2.42E-03 & 2.62E-03 & $6.36 E-03 \pm 1.08 E-04$ \\
\hline Adipose tissue & $4.96 \mathrm{E}-03$ & 5.59E-03 & $1.63 E-03$ & $3.25 E-03$ & 5.05E-03 & 3.59E-03 & 3.69E-03 & $1.03 E-02 \pm 1.43 E-04$ \\
\hline Muscle & $1.18 E-02$ & 3.07E-03 & $6.10 \mathrm{E}-04$ & $1.86 \mathrm{E}-03$ & $2.80 \mathrm{E}-03$ & $1.84 E-03$ & $2.45 E-03$ & $2.01 E-02 \pm 6.62 \mathrm{E}-04$ \\
\hline Adrenals & $2.20 \mathrm{E}-03$ & 5.40E-04 & $1.50 \mathrm{E}-04$ & 9.03E-03 & 4.62E-02 & $2.55 \mathrm{E}-02$ & $6.17 \mathrm{E}-03$ & $8.89 \mathrm{E}-03 \pm 2.75 \mathrm{E}-04$ \\
\hline Bladder wall & $5.18 E-03$ & $2.14 \mathrm{E}-01 \triangle$ & $9.16 \mathrm{E}-06$ & 2.61E-04 & $1.75 E-03$ & $7.31 \mathrm{E}-04$ & $2.26 \mathrm{E}-04$ & $5.98 \mathrm{E}-02 \pm 9.81 \mathrm{E}-03$ \\
\hline Blood vessel & $1.96 \mathrm{E}-02$ & 3.34E-02 & 4.13E-03 & $7.64 \mathrm{E}-02$ & $3.24 \mathrm{E}-02$ & 3.13E-02 & 5.18E-02 & $4.69 \mathrm{E}-02 \pm 4.04 \mathrm{E}-04$ \\
\hline Brain & $6.95 \mathrm{E}-04$ & $7.62 E-06$ & $1.83 E-01$ & $5.68 E-04$ & 1.05E-04 & 2.29E-04 & $7.66 \mathrm{E}-04$ & $8.25 E-02 \pm 1.29 E-03$ \\
\hline Breasts & $2.54 \mathrm{E}-03$ & 2.32E-04 & $1.38 E-03$ & $2.50 \mathrm{E}-02$ & 3.31E-03 & $9.90 \mathrm{E}-03$ & $1.81 \mathrm{E}-02$ & $7.42 E-03 \pm 1.37 E-04$ \\
\hline Bronchi & 1.27E-03 & $6.58 \mathrm{E}-05$ & $3.56 E-04$ & $2.99 \mathrm{E}-02$ & $1.51 \mathrm{E}-03$ & $3.57 E-03$ & 2.32E-02 & $4.45 E-03 \pm 1.67 E-04$ \\
\hline Esophagus & $3.22 \mathrm{E}-03$ & $1.54 \mathrm{E}-04$ & $1.84 E-03$ & 4.70E-02 & 4.72E-03 & $1.15 \mathrm{E}-02$ & 2.33E-02 & $9.79 E-03 \pm 3.39 E-04$ \\
\hline Eye balls & $1.33 E-03$ & 4.27E-05 & 2.73E-02 & $1.32 \mathrm{E}-03$ & 2.86E-04 & 6.33E-04 & $1.47 E-03$ & $1.44 \mathrm{E}-02 \pm 2.33 \mathrm{E}-04$ \\
\hline Eye lens & 8.83E-04 & 3.62E-06 & $2.15 \mathrm{E}-02$ & 2.09E-03 & 8.01E-05 & 5.33E-04 & $1.47 E-03$ & $1.11 E-02 \pm 1.72 E-04$ \\
\hline Gall Bladder & $3.95 \mathrm{E}-03$ & $1.53 \mathrm{E}-03$ & $2.27 E-04$ & 1.41E-02 & $5.80 \mathrm{E}-02$ & 8.87E-02 & $9.21 E-03$ & $2.00 \mathrm{E}-02 \pm 1.20 \mathrm{E}-03$ \\
\hline
\end{tabular}




\begin{tabular}{|c|c|c|c|c|c|c|c|c|}
\hline Heart wall & $1.62 \mathrm{E}-03$ & 1.60E-04 & 4.64E-04 & $5.45 E-01$ & $3.67 E-03$ & $9.28 \mathrm{E}-03$ & 2.08E-02 & $2.08 E-02 \pm 6.80 \mathrm{E}-03$ \\
\hline Kidney & 3.12E-03 & $1.31 \mathrm{E}-03$ & 1.05E-04 & 4.44E-03 & 6.79E-01 & $1.70 \mathrm{E}-02$ & $3.58 \mathrm{E}-03$ & $3.29 \mathrm{E}-02 \pm 1.60 \mathrm{E}-03$ \\
\hline Larynx & $1.61 \mathrm{E}-03$ & $1.56 \mathrm{E}-05$ & 1.39E-02 & $1.68 \mathrm{E}-03$ & 1.97E-04 & 4.62E-04 & 2.10E-03 & $8.92 E-03 \pm 1.62 E-04$ \\
\hline LI wall & $4.87 E-03$ & 2.01E-02 & $3.96 \mathrm{E}-05$ & $1.15 E-03$ & 1.12E-02 & $4.53 \mathrm{E}-03$ & 9.00E-04 & $1.15 E-02 \pm 6.44 E-04$ \\
\hline Liver & 2.17E-03 & 6.47E-04 & 2.49E-04 & 1.19E-02 & $1.76 \mathrm{E}-02$ & 1.70E-01 & $1.02 E-02$ & $2.49 \mathrm{E}-02 \pm 2.54 \mathrm{E}-03$ \\
\hline Lung & 2.85E-03 & 1.70E-04 & 8.03E-04 & 2.64E-02 & $3.76 \mathrm{E}-03$ & 1.04E-02 & 2.00E-01 & $1.48 \mathrm{E}-02 \pm 1.47 \mathrm{E}-03$ \\
\hline Lymph node & $1.57 \mathrm{E}-03$ & 3.84E-03 & $5.23 E-04$ & $5.11 \mathrm{E}-03$ & $4.84 \mathrm{E}-03$ & $2.85 \mathrm{E}-03$ & $3.68 \mathrm{E}-03$ & $4.07 \mathrm{E}-03 \pm 9.20 \mathrm{E}-05$ \\
\hline $\begin{array}{c}\text { Oral cavity } \\
\text { layer }\end{array}$ & 5.39E-03 & 5.18E-05 & 3.07E-02 & $6.26 \mathrm{E}-03$ & 9.09E-04 & 2.05E-03 & 7.09E-03 & $2.30 \mathrm{E}-02 \pm 4.61 \mathrm{E}-04$ \\
\hline Pancreas & 2.58E-03 & 1.70E-03 & 1.31E-04 & 6.13E-03 & 4.01E-02 & 2.35E-02 & 3.83E-03 & $9.00 E-03 \pm 2.86 E-04$ \\
\hline Pituitary & $1.60 \mathrm{E}-03$ & 1.49E-15 & 7.44E-02 & $9.87 E-04$ & $1.63 E-04$ & $3.65 \mathrm{E}-04$ & $9.73 E-04$ & $3.57 \mathrm{E}-02 \pm 5.59 \mathrm{E}-04$ \\
\hline \multicolumn{9}{|l|}{ Gland } \\
\hline Salivary Gland & 2.27E-03 & 2.57E-05 & $1.62 E-02$ & 2.22E-03 & 3.28E-04 & $7.76 \mathrm{E}-04$ & $2.96 \mathrm{E}-03$ & $1.11 E-02 \pm 2.11 E-04$ \\
\hline SI wall & 2.77E-03 & $1.70 \mathrm{E}-02$ & 4.29E-05 & $1.70 \mathrm{E}-03$ & $1.34 \mathrm{E}-02$ & $5.40 \mathrm{E}-03$ & 1.13E-03 & $7.97 \mathrm{E}-03 \pm 6.45 \mathrm{E}-04$ \\
\hline Bone surface & 4.22E-03 & 3.36E-03 & $6.35 \mathrm{E}-03$ & 3.13E-03 & 3.30E-03 & 2.72E-03 & 4.45E-03 & $1.07 E-02 \pm 1.77 E-04$ \\
\hline Bone marrow & 8.82E-03 & 1.03E-02 & 1.19E-02 & 9.19E-03 & $9.61 E-03$ & 8.02E-03 & 1.05E-02 & $2.28 \mathrm{E}-02 \pm 3.17 \mathrm{E}-04$ \\
\hline Bone cartilage & 4.47E-03 & 4.90E-03 & $7.81 \mathrm{E}-04$ & $5.55 E-03$ & $5.41 \mathrm{E}-03$ & $5.66 \mathrm{E}-03$ & $4.32 \mathrm{E}-03$ & $9.35 \mathrm{E}-03 \pm 1.30 \mathrm{E}-04$ \\
\hline Spinal cord & 2.21E-03 & 1.38E-04 & $3.28 \mathrm{E}-03$ & 4.92E-03 & $5.00 \mathrm{E}-03$ & $4.20 \mathrm{E}-03$ & $6.45 E-03$ & $6.08 E-03 \pm 1.27 E-04$ \\
\hline Spleen & 2.73E-03 & 5.16E-04 & 2.69E-04 & $1.37 \mathrm{E}-02$ & 2.72E-02 & $7.42 \mathrm{E}-03$ & $1.26 \mathrm{E}-02$ & $7.34 \mathrm{E}-03 \pm 6.79 \mathrm{E}-05$ \\
\hline Stomach wall & $2.66 \mathrm{E}-03$ & $1.15 E-03$ & 2.25E-04 & $1.91 \mathrm{E}-02$ & 2.38E-02 & $2.20 \mathrm{E}-02$ & 8.80E-03 & $8.88 \mathrm{E}-03 \pm 1.40 \mathrm{E}-04$ \\
\hline Thymus & $1.88 E-03$ & $4.85 \mathrm{E}-05$ & 1.07E-03 & 2.09E-02 & 9.12E-04 & $2.46 \mathrm{E}-03$ & 1.51E-02 & $5.01 \mathrm{E}-03 \pm 1.72 \mathrm{E}-04$ \\
\hline Thyroid & 3.77E-03 & 4.51E-05 & 3.79E-03 & $9.24 \mathrm{E}-03$ & 9.00E-04 & 2.07E-03 & $1.16 \mathrm{E}-02$ & $8.71 \mathrm{E}-03 \pm 2.38 \mathrm{E}-04$ \\
\hline Tongue & $1.54 \mathrm{E}-03$ & $1.76 \mathrm{E}-05$ & 1.03E-02 & 2.04E-03 & 2.89E-04 & 7.18E-04 & 2.33E-03 & $7.26 \mathrm{E}-03 \pm 1.39 \mathrm{E}-04$ \\
\hline Tonsil & 2.00E-03 & 2.51E-05 & 1.49E-02 & $1.45 E-03$ & 2.38E-04 & 4.42E-04 & 2.06E-03 & $9.99 \mathrm{E}-03 \pm 1.90 \mathrm{E}-04$ \\
\hline Trachea & 4.19E-03 & $9.50 \mathrm{E}-05$ & $3.42 \mathrm{E}-03$ & 2.52E-02 & $1.44 \mathrm{E}-03$ & 3.58E-03 & 2.45E-02 & $1.04 \mathrm{E}-02 \pm 2.71 \mathrm{E}-04$ \\
\hline Ureter & $3.46 \mathrm{E}-03$ & 1.71E-02 & 4.21E-05 & $1.51 \mathrm{E}-03$ & $1.81 \mathrm{E}-02$ & 5.49E-03 & $1.15 E-03$ & $9.27 \mathrm{E}-03 \pm 6.17 \mathrm{E}-04$ \\
\hline Ovaries & $5.21 \mathrm{E}-03$ & 3.85E-02 & 2.49E-06 & $1.57 \mathrm{E}-04$ & 1.39E-03 & $6.55 \mathrm{E}-04$ & $1.75 E-04$ & $1.37 \mathrm{E}-02 \pm 1.37 \mathrm{E}-03$ \\
\hline Uterine wall & 5.12E-03 & 8.93E-02 & $1.04 \mathrm{E}-05$ & 2.30E-04 & $1.69 \mathrm{E}-03$ & 7.13E-04 & 2.08E-04 & $2.04 \mathrm{E}-02 \pm 3.61 \mathrm{E}-03$ \\
\hline
\end{tabular}




\section{Figures}
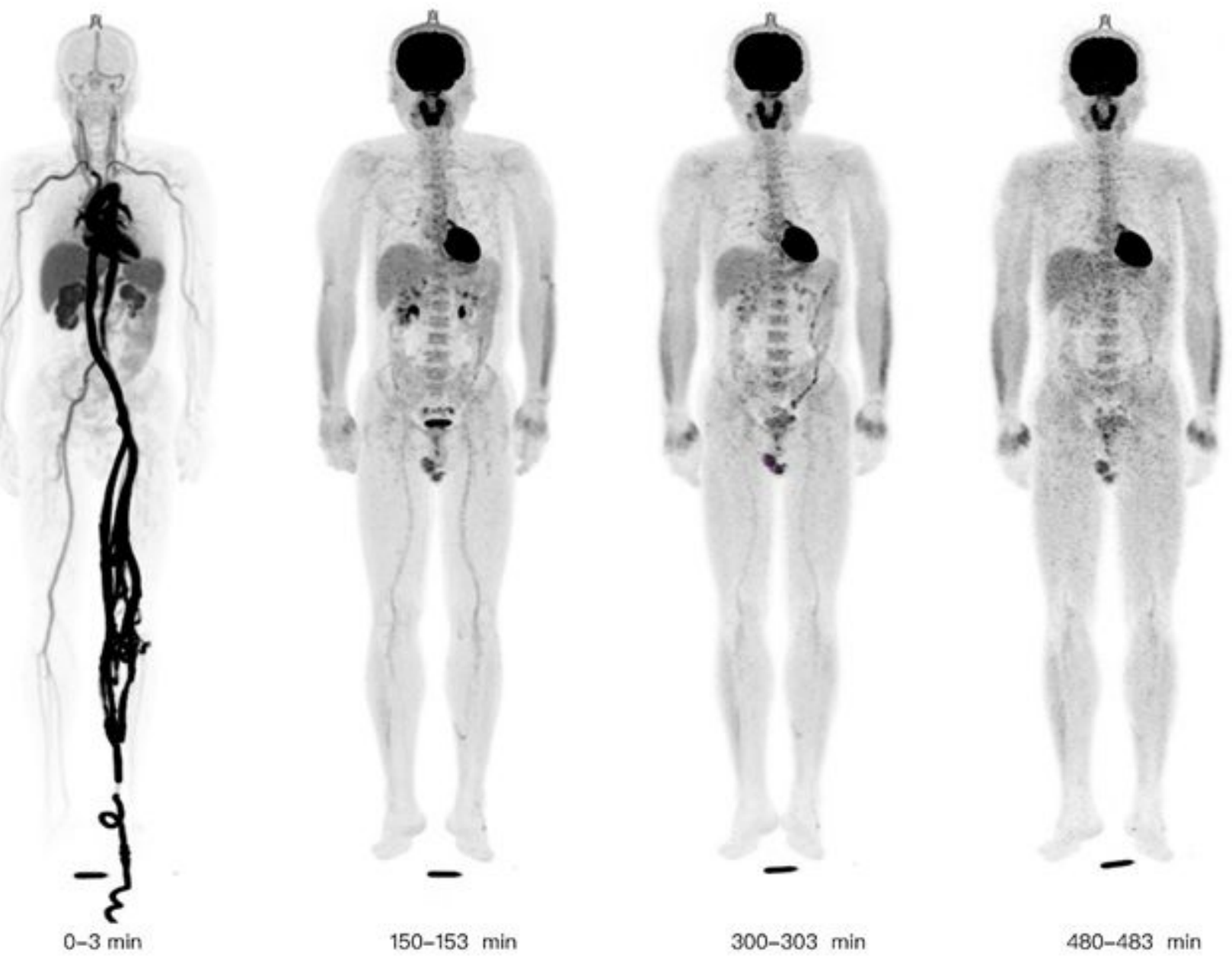

Figure 1

Reconstructed dynamic PET images (Ordered Subset Expectation-maximization Maximum-intensity Projection) of early 3 minute, 150 153 minute, 300 303 minute, 480 483minute. 

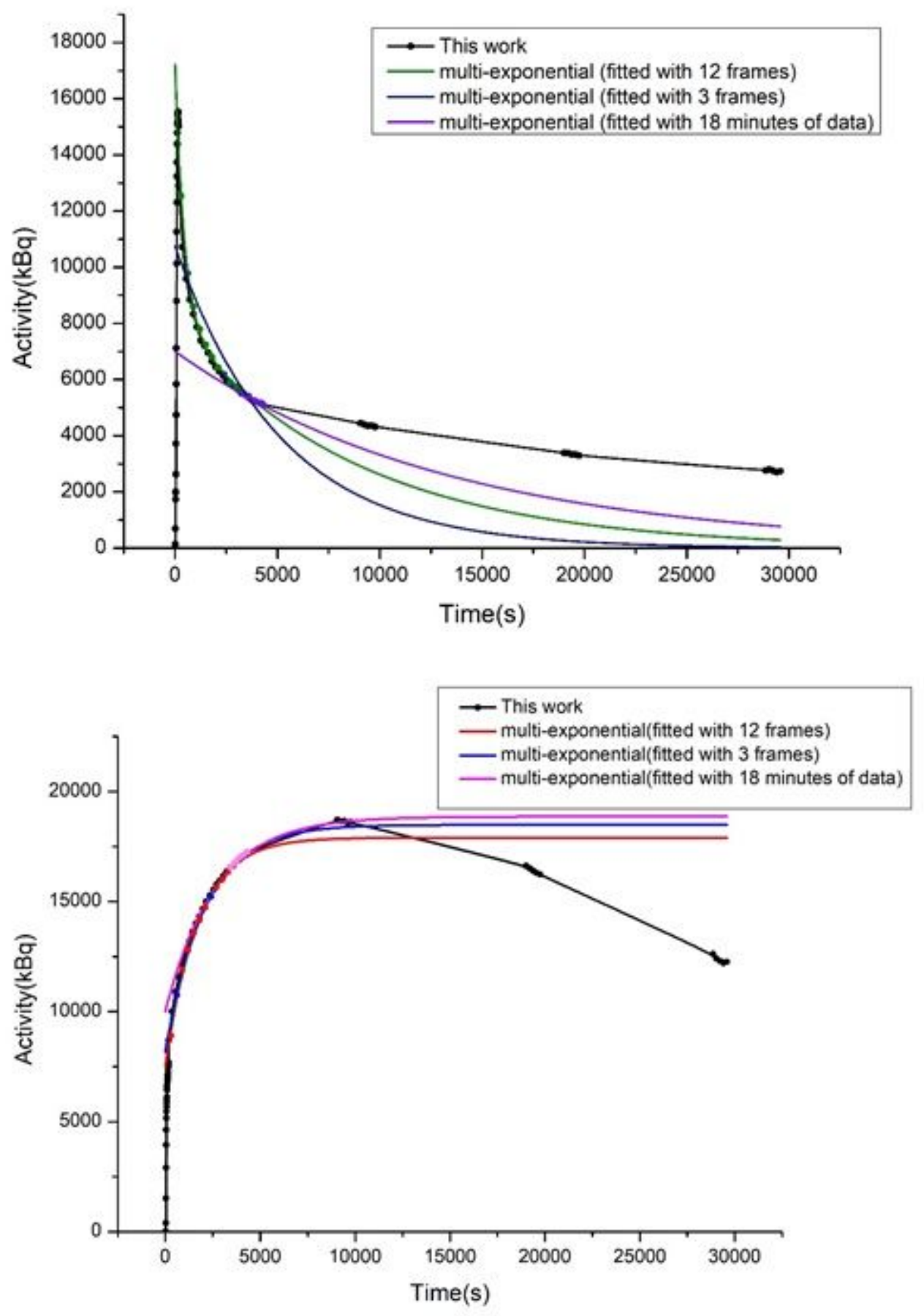

Figure 2

A comparison between multi-exponential method with $12 * 120 \mathrm{~s}, 3 * 180$ s and 18 minutes of data and spline method (8 hours) in liver data(left) and brain data(right) fitting in one of the studies (decay corrected). 


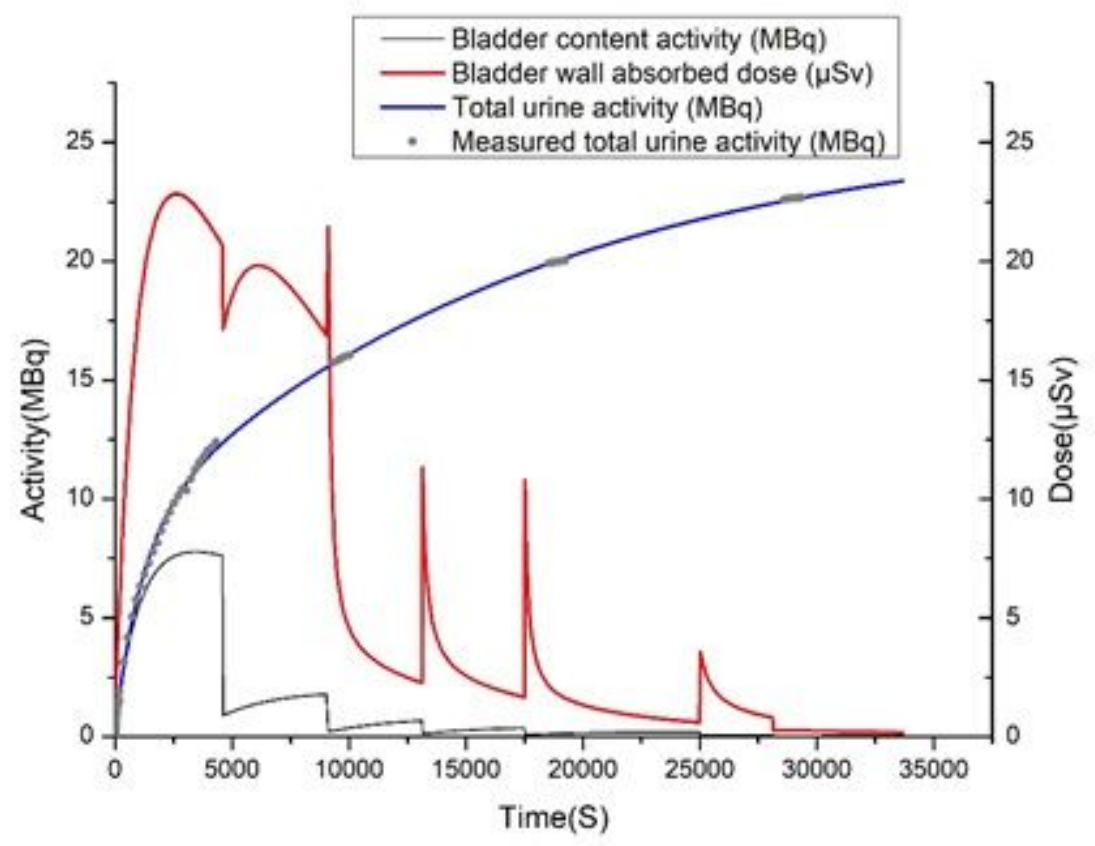

Figure 3

Representative time activity curve of bladder content (not decay corrected), fitting total urine activity and measured total urine activity (including bladder urine and excreted urine, decay corrected) and absorbed dose to the bladder wall.

\section{Supplementary Files}

This is a list of supplementary files associated with this preprint. Click to download.

- SupplementalData12.docx 